\title{
Factors associated with gerontological career choice: The role of curriculum type and students' attitudes
}

\author{
Jung-Ah Lee*1, Dana Rose Garfin ${ }^{1}$, Stephanie Vaughn ${ }^{2}$, Young-Shin Lee ${ }^{3}$ \\ ${ }^{1}$ Sue and Bill Gross School of Nursing, University of California-Irvine, Irvine, CA, United States \\ ${ }^{2}$ School of Nursing, California State University-Fullerton, Fullerton, CA, United States \\ ${ }^{3}$ School of Nursing, San Diego State University, San Diego, CA, United States
}

Received: October 10, 2017

Accepted: November 14, $2017 \quad$ Online Published: November 26, 2017

DOI: $10.5430 /$ jnep.v8n4p1

URL: https://doi.org/10.5430/jnep.v8n4p1

\begin{abstract}
Background and objective: Caring for a growing aging population presents a challenge in contemporary health care. This study aims to identify factors associated with nursing student's career choice in older adult care and predictors of attitudes toward older adults. Such information is critical to inform effective gerontological nursing education.

Methods: Undergraduate nursing students $(\mathrm{N}=411)$ from three nursing schools in California participated in a cross-sectional, web-based survey.

Results: In covariate-adjusted analyses, students who had prior experiences taking gerontology-related courses, working with older adults, living with older adults, being confident in providing older adults care, and having lower negative attitudes toward older adults were more likely to consider a future career in gerontological nursing. Students' confidence in older adult care was negatively correlated with negative attitudes towards older adults.

Conclusions: To increase students' career choice in gerontology, nursing schools should provide more gerontology content in nursing curricula and explore avenues to increase student confidence in older adult care.
\end{abstract}

Key Words: Attitude, Career goals, Gerontological nursing, Nursing education, Nursing students, Older adults

\section{INTRODUCTION}

With greater human longevity and a rapidly increasing older population, demands for healthcare for the aging are exponentially increasing. The number of persons aged 65 years and older is expected to increase from approximately 40 million in 2010 to an estimated 71 million by $2030 .^{[1]}$ As this trend increases, so does the demand for healthcare specialists trained to provide care for this population and to meet their unique needs: In the United States, more than $80 \%$ of adults aged 65 years or older have at least one chronic medical condition, and 50\% have at least two. ${ }^{[1]}$ More than half of the hospital beds in the United States are occupied by older adults. Parallel to this increasing demand for geriatric healthcare is a shortage of nurses in general and a particular dearth in those trained in gerontological nursing. This poses a serious issue for public health. ${ }^{[2]}$ Several reports indicate that 135,000 registered nurse (RN) vacancies existed in long-term care and hospital settings in 2007; this nursing shortage is further projected to grow to 260,000 by $2025 .{ }^{[2]}$ With respect to care for older adults, less than $1 \%$ of RNs are certified in geriatric/gerontological nursing. ${ }^{[3]}$

One reason for this shortage may be widespread negative social views toward older adults that may hamper the re-

\footnotetext{
*Correspondence: Jung-Ah Lee; Email: jungahl@uci.edu; Address: Sue and Bill Gross School of Nursing, University of California-Irvine, Irvine, CA, United States.
} 
cruitment of qualified health care providers in gerontological fields. ${ }^{[4]}$ Research indicates that a majority of older adults frequently encounter incidents of ageism and are treated by others as ailing and frail in the United States and Canada. ${ }^{[5,6]}$ Such treatment hampers the facilitation of effective care for older adults, which includes bolstering confidence, engagement, and adaption for older adults in the face of new medical challenges. Younger adults, such as college-aged individuals who are choosing their career specialties, tend to originate more instances of ageism relative to other age groups ${ }^{[7]}$ and often report higher negative attitudes towards older adults. These negative attitudes of younger individuals towards older adults are a likely factor contributing to the shortage of nurses trained and willing to provide care for older adults, yet few studies have explored this particular relationship.

One potential avenue to bolster positive attitudes of young people towards older adults may be educational experiences that increase knowledge and provide opportunities for crossgenerational experiences. Prior research has demonstrated that college students in health-related majors who had taken a gerontology course improved their knowledge about older adults, developed positive attitudes toward aging, ${ }^{[8,9]}$ and reduced their negative attitudes toward older adults. ${ }^{[10,11]}$ Yet other studies found that educational experience did not change students' attitudes toward aging. ${ }^{[12-14]}$ Moreover, a study of masters' students in social work indicated that while gerontology course content improved attitudes towards other adults, it did not increase interest in gerontology as a career choice. ${ }^{[15]}$ Taken together, these findings suggest a need for further research aimed at understanding nursing students' perceptions of older adults and how health care education can be used to both improve attitudes and encourage much needed careers in this specialization. Moreover, more research needs to explore nursing students' perceptions of working in diverse healthcare settings for older adults (e.g., acute care settings, community clinics, assisted living, or long-term care facilities). ${ }^{[16]}$

Despite the potential for nursing programs to intervene towards this end, nursing students in undergraduate programs appear to have limited educational opportunities that could facilitate more positive attitudes toward the elderly..$^{[4,17]}$ Moreover, nursing students are likely to encounter unwell older adults in acute care facilities, thus their perceptions are often based on older adults who are sick and frail, ${ }^{[18,19]}$ potentially exacerbating negative perceptions of the elderly. This phenomenon has been documented in nurses working in acute or long-term care settings, who also develop negative attitudes toward older patients. ${ }^{[19,21]}$ A key challenge in nursing curricula is how to provide educational experiences that promote positive attitudes, rather than reinforce negative stereotypes.
One plausible avenue to promote gerontological education is the incorporation of standalone gerontology courses into nursing program curricula. It has been reported that approximately half of nursing programs include a gerontology course as a standalone course (i.e., a course that specifically focuses on gerontology) and the other half integrate gerontology content into other nursing courses ${ }^{[22,23]}$ (e.g., fundamental nursing, medical and surgical nursing, critical care nursing, community health nursing, mental health nursing, and leadership and management in nursing ${ }^{[24]}$ ). However, it is unclear whether these efforts to include gerontology in nursing education increase positive attitudes or encourage nursing students' career choices for elder adult care. Importantly, it is largely unknown whether this information is retained, and whether this retention increases career choices in older adult care or reduces negative attitudes.

\section{Purpose of the study}

This study seeks to identify factors associated with nursing students' career choice in older adult care. More specifically, we examine whether:

(1) type of nursing curriculum (standalone vs. integrated) is associated with student's likelihood to consider a career in gerontological nursing.

(2) negative attitudes towards the elderly are related to nursing students' career choices.

(3) nursing students retain key information regarding older adult care that is presented in their curriculum, and whether this retention predicts career choice in older adult care.

\section{Methods}

A cross-sectional web-based survey of nursing students' future career choice of caring for older adults and variables that may be associated with this choice was administered to nursing students at three Southern California universities. All three schools offer undergraduate nursing programs conferring baccalaureate science (B.S.) degrees in nursing to their students. The Institutional Review Board (IRB) at each respective university approved the study protocol.

Recruitment. Nursing students (aged 18 years and older) at schools with standalone gerontology courses (schools A and B) were recruited in class to participate in the survey in exchange for extra credit; students were offered an alternative extra credit option if they chose not to participate. Students were not penalized in any way if they chose the alternative extra credit. Students (aged 18 years and older) with integrated gerontology curriculum (school C) were invited to take the survey during several rounds of recruitment: The first round was sent to all students in the nursing school. 
Then, to increase sample size, students in a community health nursing course were invited to participate. Students at school C were not offered extra credit in order to uniformly administer the survey and insure anonymity. Participation was entirely voluntary at all three schools. Non-verbal consent (which included information about study purpose, procedures, risks and benefits) was obtained online at the time of survey recruitment. Information regarding study purpose and procedures was provided for all participating students via on-line materials. The web-based surveys were conducted over two quarters at each nursing school. The response rates of nursing school A and B was almost 99\%. The response rate at nursing school $\mathrm{C}$ would not be calculated because we were unable to track the number of students who received the recruitment email given the anonymous nature of our survey.

Standalone gerontology course. Schools A and B provide a 2-credit standalone gerontology course over a semester and quarter, respectively. School A provided an additional one unit clinical component. Course content focuses on the phenomena of healthy aging and emphasizes health promotion and illness prevention for older adults including identification of disease risk factors associated with aging and reasons that the elderly are not able to remain in their homes. The older adult is viewed as a healthy and productive individual in their community who are willing to share their lifetime knowledge, value system, and cultural beliefs to younger generations.

Survey instrument. The survey was designed through an iterative process between lead authors (J.A. Lee \& S. Lee). Standardized measures were selected based on prior research.

Student's career choice. Students were asked "in your future career, have you considered working with older adults?" Responses were dichotomized 0 (no) and 1 (yes).

Negative attitudes towards older adults. The negative attitudes subscale of the Kogan's Attitudes Toward Older People $(1961)^{[25]}$ assessed norms and individual differences, stereotypes of older adults, and misconceptions about older adults. The negative attitudes subscale consists of 17 statements. Response options are provided on a 7-point Likert scale: 1 (strongly disagree) to 7 (strongly agree), with a higher score indicates a higher negative attitude. Reliability was very good in this study $\alpha=.88$, consistent with prior research. ${ }^{[24]}$

Specific gerontology knowledge. Retention of specific gerontological knowledge was assessed via a question asking participants to read a brief case study and identify the appropriate tool used to identify functional assessment [the answer was Katz Index of Independence in Activities of Daily Living (ADL)]. Answers were then coded 0 (incorrect answer) and

Published by Sciedu Press
1 (correct answer).

Prior gerontological education. Participants were asked:

1) "How well do you feel that your nursing education has prepared you to care for older adults?" Responses were dichotomized: 0 (somewhat, very little, or not at all) and 1 (pretty confident or very much).

2) "How confident are you in your ability to provide care for older adults?" Responses were dichotomized: 0 (very little neutral) and 1 (pretty confident or very much).

3) "ADLs are the key functional parameters of interest for older adults who have some level of deficits. Student's ability to measure one's ADLs must be broad enough to capture the relevant areas of change. How confident are you applying or using functional status instrument to older adults?" Responses were dichotomized: 0 (not at all, very little, somewhat, neutral) and 1 (pretty confident, very much).

Experiences with older adults. Participants were asked:

4) "How comfortable are you communicating with older adults who have the same ethnicity as you?" Responses were dichotomized: 0 (not at all comfortable, somewhat comfortable, neither) and 1 (somewhat comfortable, very comfortable).

5) "How comfortable are you communicating with older adults who have a different ethnic background than you?" Responses were dichotomized: 0 (not at all comfortable, somewhat comfortable, neither) and 1 (somewhat comfortable, very comfortable).

6) "How often do you communicate with older adults in a personal or social context?" Responses were dichotomized 0 (never, rarely, occasionally/less than once a month) and 1 (regularly/at least once a month, regularly/at least once a week).

Demographics. Participants reported their gender, age, ethnicity, and year in school.

\section{Statistical analyses}

Descriptive statistics were calculated for sample demographics and survey question responses. Tests of between group differences that compared students who were in a nursing program with standalone gerontology curriculum to those who were in a nursing program with integrated gerontology curriculum were conducted. Next, bivariate logistic regression analyses examined the relationship between key study variables and predictors of student's consideration of a nursing career in older adult care $(0=$ no, has not considered; $1=$ yes, has considered). Significant predictors of career choice were then combined into a multiple logistic regression. 


\section{RESUlts}

Table 1 presents detailed information regarding the demographic characteristics of the sample. Participants were primarily juniors $(37.97 \%)$ or seniors $(59.31 \%)$ in college, with a mean age of $24(\mathrm{SD}=5.11)$. The vast majority was female $(85.37 \%)$. The sample was multi-racial, split primarily between White/non-Hispanics (43.18\%) and Asian/nonHispanic (40.69\%) with few Hispanics (5.71\%), Black/nonHispanics (1.74\%) or Mixed/other (8.68\%).

Table 2 presents comparison of key study variables and type of gerontological nursing course (standalone or integrated curriculum). Group differences between students in standalone curriculum and integrated curriculum were significant for several variables. Those who were in a standalone course had greater odds of reporting the correct answer to the ADL instrument question $(\mathrm{OR}=3.74, \mathrm{SE}=1.11, p<.001,95 \%$ CI, 2.08, 6.70). Participants who were in a standalone course also had lower odds of reporting high frequent communication with older adults $(\mathrm{OR}=0.43, \mathrm{SE}=.12, p<.003,95 \%$ CI, $0.25,0.74)$.

Table 1. Sample demographic characteristics and gerontology-related experiences $(\mathrm{N}=411)^{*}$

\begin{tabular}{|c|c|c|}
\hline & Frequency & Percent \\
\hline \multicolumn{3}{|l|}{ Year in Program } \\
\hline Junior & 153 & $37.97 \%$ \\
\hline Senior & 239 & $59.31 \%$ \\
\hline Other & 11 & $2.73 \%$ \\
\hline \multicolumn{3}{|c|}{ Age (year): Mean $=24$ ( \pm 5.11), Median $=22$, Range: $19-51$} \\
\hline \multicolumn{3}{|l|}{ Gender } \\
\hline Male & 60 & $14.63 \%$ \\
\hline Female & 350 & $85.37 \%$ \\
\hline \multicolumn{3}{|l|}{ Race/Ethnicity } \\
\hline White/Non-Hispanic & 174 & $43.18 \%$ \\
\hline Asian/Non-Hispanic & 164 & $40.69 \%$ \\
\hline Hispanic & 23 & $5.71 \%$ \\
\hline Black/Non-Hispanic & 7 & $1.74 \%$ \\
\hline Mixed or other & 35 & $8.68 \%$ \\
\hline \multicolumn{3}{|l|}{ Marital status } \\
\hline Single & 360 & $88.02 \%$ \\
\hline Married & 49 & $11.98 \%$ \\
\hline \multicolumn{3}{|l|}{ US Born } \\
\hline Yes & 330 & $81.08 \%$ \\
\hline No & 77 & $18.92 \%$ \\
\hline \multicolumn{3}{|l|}{ US Living } \\
\hline Entire life & 324 & $79.80 \%$ \\
\hline Some of life & 82 & $20.20 \%$ \\
\hline \multicolumn{3}{|c|}{ School (Type of gerontological content in nursing curriculum) } \\
\hline A (standalone course) & 187 & $45.50 \%$ \\
\hline B (standalone course) & 135 & $32.85 \%$ \\
\hline C (integrated curriculum) & 89 & $21.65 \%$ \\
\hline \multicolumn{3}{|c|}{ Have you previously taken a gerontology related course in another department other than nursing program? } \\
\hline Yes & 39 & $10.00 \%$ \\
\hline No & 351 & $90.00 \%$ \\
\hline \multicolumn{3}{|c|}{ Have you ever lived with people age 65 years or older? } \\
\hline Yes & 165 & $40.54 \%$ \\
\hline No & 242 & $59.46 \%$ \\
\hline \multicolumn{3}{|c|}{ Have you worked for older adults not including the ones you worked with during your nursing program? } \\
\hline Yes & 164 & $40.10 \%$ \\
\hline No & 245 & $59.90 \%$ \\
\hline \multicolumn{3}{|c|}{ Regularly communicate with older adults in a personal or social context } \\
\hline Regular & 267 & $64.98 \%$ \\
\hline Not regularly & 144 & $35.04 \%$ \\
\hline
\end{tabular}

* $\mathrm{N}$ varies due to missing data. 
Table 2. Comparison of key study variables and type of gerontological nursing course $(\mathrm{N}=411)^{*}$

\begin{tabular}{|c|c|c|c|c|c|c|}
\hline & \multicolumn{2}{|c|}{$\begin{array}{l}\text { Students in standalone } \\
\text { gerontological nursing } \\
\text { curriculum } \\
(\mathrm{n}=322)\end{array}$} & \multicolumn{2}{|c|}{$\begin{array}{l}\text { Students in integrated } \\
\text { gerontological nursing } \\
\text { curriculum } \\
(\mathbf{n}=\mathbf{8 9})\end{array}$} & \multicolumn{2}{|c|}{$\begin{array}{l}\text { Total } \\
(N=411)\end{array}$} \\
\hline & $\mathbf{n}$ & $\%$ & $\mathbf{n}$ & $\%$ & $\mathbf{n}$ & $\%$ \\
\hline Have considered a career in older adult care & $207 / 272$ & 78.35 & $65 / 272$ & 23.90 & $272 / 411$ & 66.18 \\
\hline Feel that nursing has provided preparation for a career in geriatric nursing & 187 & 80.60 & 45 & 19.40 & 232 & 56.45 \\
\hline Confident in ability to provide care for older adults & 239 & 77.85 & 68 & 22.15 & 307 & 74.70 \\
\hline Confident in applying ADL instruments for older adult care & 196 & 78.71 & 53 & 21.29 & 249 & 60.58 \\
\hline Correct answer to $\mathrm{ADL}$ instrument question ${ }^{\dagger}$ & 145 & 90.06 & 16 & 9.94 & 161 & 39.17 \\
\hline Comfortable communicating with older adults of similar ethnic background & 304 & 77.75 & 87 & 22.25 & 391 & 95.13 \\
\hline Comfortable communicating with adults of a different ethnic background & 294 & 77.78 & 84 & 22.22 & 378 & 91.97 \\
\hline Frequently communicates with older adults in a personal or social context & 197 & 73.78 & 70 & 26.22 & 267 & 64.96 \\
\hline
\end{tabular}

${ }^{*} \mathrm{~N}$ varies due to missing data. ${ }^{\dagger} \chi^{2}(1)=21.42, p<.001 ;{ }^{\dagger} \chi^{2}(1)=9.35, p=.002$

Table 3 presents descriptive comparisons of key predictor variables and student's report of future career consideration in older adult care $(0=$ no, has not considered; yes $=$ has considered). Several of these independent variables were significant predictors of student career choice at the bivariate level. Students aged 31-40 were more likely to report consideration of a career in gerontological nursing $(\mathrm{OR}=4.20, p=$ $.021 ; 95 \% \mathrm{CI}, 1.23,14.25)$. Those who had considered a career in older adult care had lower negative attitudes towards older adults $(\mathrm{M}=37.48, \mathrm{SD}=10.37)$ compared to those who had not considered a career in older adult care $(\mathrm{M}=$ $34.55, \mathrm{SD}=9.30$ ); this difference was statistically significant, $t(409)=2.90, p=.004$. Those who have previously taken a gerontology related course in another department were more likely to consider a career in older adult care $(\mathrm{OR}=3.99, p=$ $.005 ; 95 \% \mathrm{CI}, 1.53-10.43$ ), as were those who perceived that nursing school has prepared them to work with older adults $(\mathrm{OR}=1.89, p=.002,95 \% \mathrm{CI}, 1.25-2.86)$, those who worked with older adults outside of nursing clinical practicum $(\mathrm{OR}=$ $2.29, p<.001,95 \% \mathrm{CI}, 1.47-3.56)$, those who had experience living with older adults $(\mathrm{OR}=1.72, p=.014,95 \% \mathrm{CI}, 1.11$ 2.64), those who were confident nursing education has given them the ability to provide care for older adults $(\mathrm{OR}=1.89$, $p=.002,95 \%$ CI, 1.25-2.86), and those who communicate with older adults on a regular basis $(\mathrm{OR}=1.78, p=.007$, 95\% CI, 1.17-2.72). Race/Ethnicity was not a significant predictor of choosing a career in older adults (all ps > .10).

Table 3. Bivariate relationships between key predictor variables and consideration of gerontological nursing career choice $(\mathrm{N}=411)^{*}$

\begin{tabular}{|c|c|c|c|c|c|c|}
\hline & \multicolumn{6}{|c|}{ Considering a career choice in older adult care? } \\
\hline & \multicolumn{2}{|c|}{$\begin{array}{l}\text { Yes, considering } \\
\mathrm{n}=272\end{array}$} & \multicolumn{2}{|c|}{$\begin{array}{l}\text { No, not considering } \\
\mathrm{n}=139\end{array}$} & \multicolumn{2}{|l|}{$\begin{array}{l}\text { Total } \\
\mathbf{N}=\mathbf{4 1 1}\end{array}$} \\
\hline & $\mathbf{N}$ & $\%$ & $\mathbf{n}$ & $\%$ & $\mathbf{n}$ & $\%$ \\
\hline \multicolumn{7}{|l|}{$\operatorname{Age}^{\dagger}$} \\
\hline$\leq 30$ & $241 / 373$ & 64.61 & $132 / 373$ & 35.39 & $373 / 411$ & 90.75 \\
\hline $31-40$ & 23 & 88.46 & 3 & 11.54 & 26 & 6.33 \\
\hline$\geq 41$ & 8 & 66.67 & 4 & 33.33 & 12 & 2.92 \\
\hline $\begin{array}{l}\text { Marital status } \\
(0=\text { not married; } 1=\text { married })\end{array}$ & 38 & 77.55 & 11 & 22.45 & 49 & 11.98 \\
\hline Previously took a gerontology course in another department ${ }^{\ddagger}$ & 35 & 87.50 & 5 & 12.50 & 40 & 9.78 \\
\hline $\begin{array}{l}\text { Feel that nursing education has provided adequate preparation for gerontological } \\
\text { care }\end{array}$ & 168 & 72.41 & 64 & 27.59 & 232 & 56.45 \\
\hline Has experience working with older adults outside of clinical practicum\# & 126 & 76.83 & 38 & 23.17 & 164 & 40.0 \\
\hline Prior experience living with older adults ${ }^{\dagger}$ & 121 & 73.33 & 44 & 26.67 & 165 & 40.54 \\
\hline Confident to provide care for older adults\# & 224 & 72.96 & 83 & 27.04 & 307 & 74.70 \\
\hline $\begin{array}{l}\text { Confident to apply activities in daily living (ADL) instruments to care for older } \\
\text { adults }\end{array}$ & 172 & 69.08 & 77 & 30.92 & 249 & 60.58 \\
\hline Provided correct answer to ADL instrument question & 103 & 63.98 & 58 & 36.02 & 161 & 39.17 \\
\hline Comfortable communicating with older adults who are the same ethnicity as you & 260 & 66.50 & 131 & 33.50 & 391 & 95.13 \\
\hline Comfortable communicating with older adults who are a different ethnicity as you & 250 & 66.14 & 128 & 33.86 & 378 & 91.97 \\
\hline Regularly communicates with older adults in a personal or social context ${ }^{\ddagger}$ & 189 & 70.79 & 78 & 29.21 & 267 & 64.96 \\
\hline
\end{tabular}


Table 4 presents results from the multiple regression analyses to examining factors associated with the career choice in older adult care. Significant factors associated with students' career choice in older adult care were: taking gerontology related courses in another department $(\mathrm{OR}=4.43, p=.004$, 95\% CI, 1.61-12.2), prior work experiences with older adults $(\mathrm{OR}=1.91, p=.009,95 \% \mathrm{CI}, 1.17-3.09)$, prior experience living with older adults $(\mathrm{OR}=1.77, p=.02,95 \% \mathrm{CI}, 9-2.85)$, being confident in ability to provide care for older adults (OR $=3.07, p<.001,95 \% \mathrm{CI}, 1.78-5.28)$, and negative attitudes toward older adults $(\mathrm{OR}=0.97, p=.018,95 \% \mathrm{CI}, 0.95-0.99)$. These analyses controlled for age, gender, standalone vs. integrated gerontology course, regular communication with older adults and feeling that nursing education has provided adequate preparation for caring for older adults.

Given prior work emphasizing the potential for negative attitudes towards older adults to reduce their likelihood of choosing a career in gerontological nursing, we conducted supplementary analyses to examine predictors of negative attitudes towards older adults. In covariate-adjusted multiple regression analyses, confidence in caring for older adults was negatively correlated with negative attitudes towards older adults $(b=-2.74, \mathrm{SE}=1.21,95 \% \mathrm{CI},-5.12,-0.35, p=.025)$. Those who reported higher confidence had, on average, lower negative attitudes.

Table 4. Multiple logistic regression analyses of nursing student's consideration of a career in gerontological nursing $(\mathrm{N}=$ $395)^{*}+$

\begin{tabular}{lllll}
\hline & OR & SE & 95\% CI & $\boldsymbol{p}$-value \\
\hline Age\# & 1.01 & 0.03 & $0.96,1.06$ & .816 \\
Female gender & 0.86 & 0.29 & $0.45,1.64$ & .643 \\
Standalone course $\neq$ & 0.81 & 0.21 & $0.49,1.33$ & .403 \\
Previously took gerontology related courses in another department & 4.43 & 2.29 & $1.61,12.2$ & .004 \\
Regularly communicate with older adults in a personal or social context & 1.22 & 0.30 & $0.75,1.97$ & .422 \\
Previously worked with older adults outside of nursing education & 1.91 & 0.47 & $1.17,3.09$ & .009 \\
Prior experience living with older adults & 1.77 & 0.43 & $1.09,2.85$ & .020 \\
Confident in ability to provide care for older adult & 3.07 & 0.85 & $1.78,5.28$ & $<.001$ \\
Feel that nursing education has provided adequate preparation for gerontological care & 1.39 & 0.35 & $0.84,2.29$ & .198 \\
Negative attitudes ${ }^{\dagger \dagger}$ & 0.97 & 0.01 & $0.95,0.99$ & .018 \\
Constant & 1.08 & 0.90 & $0.21,5.49$ & .925 \\
\hline
\end{tabular}

*N differs from 411 due to missing data; †Outcome variable 0 (has not considered a career in gerontology), 1 (has considered a career in gerontology \#Age was included as a continuous variable

$\ddagger 0$ = no, integrated gerontology content in nursing curriculum; $1=y e s$, standalone course in nursing curriculum

†† Score on Kogan's Attitudes Toward Older People Negative Scale

\section{Discussion}

This study sought to identify factors associated with nursing students' career choice in gerontological nursing. Consideration of a career in gerontology was associated with prior experiences with older adults (working with older adults, living with older adults), educational experiences (taking gerontology-related courses in other departments, confidence in the ability to care for older adults) and lower negative attitudes toward older adults. Type of gerontological nursing education (i.e., standalone course vs. integrated curricula) was not associated with nursing students' future career choice, suggesting that either method of gerontological education could be used to increase students' confidence in working with older adults, provide more experiences interacting with older adults, and target a reduction in negative attitudes. The results of nursing students' attitudes toward older adults in this study were similar to those from previous literature. ${ }^{[26,27]}$

Findings suggest several potential avenues that could be used to increase nursing student's interest in a career in older adult care. First, nursing faculty could encourage or require nursing students to take more elective courses related to gerontological concepts. Second, schools could require additional volunteer or work experiences with older adults before or during commencement of nursing education. Third, as part of the design of broader nursing program curricula, nursing programs could require the integration of gerontological content throughout student's coursework.

Results also point to several important factors that nursing programs could target when designing curricula. For example, methods for improving communication skills with older adults could be introduced and emphasized in fundamental or foundational nursing courses before students start their 
clinical rotations. More clinical work focused on improving confidence in working with adults should be incorporated into practicums. Nursing practicum should also provide more opportunities for positive interaction with older adults who are in relatively good health, rather than only working with those who are extremely sick, frail or disabled. Such opportunities might provide experiences to bolster positive schemas about older adults that could lower negative attitudes.

Yet challenges exist for nursing education with respect to implementing some of these recommendations. Nursing education tends to focus on acute care settings, while the majority of demand for geriatric nursing is in long-term care settings. Long-term care requires interdisciplinary teamwork and care coordination in settings designed to serve older adults (e.g., skilled nursing facilities, residential care, home health care, and adult day care). Yet given the dearth of trained nurses in gerontology, these teams may lack expertise in gerontology, inhibiting the most effective care. One way to combat this limitation is to introduce gerontology-related theories and skills into nursing curricula for nursing leadership, management and community health, increasing knowledge throughout the nursing team. Senior nursing students who show special interest in older adult care should be offered additional clinical rotations in the last quarter or semester of their nursing programs to reinforce knowledge and experience and bolster confidence in their own skills and in their ability to translate their specialized knowledge throughout interdisciplinary team care. For example, students could be given opportunities to work with older adults in a community setting or in an acute rehab setting where older adults are transitioning back into the broader community.

We found few differences between key variables and standalone compared to integrated coursework; one finding of note was that students in programs with a standalone course were more likely to answer a question regarding the ADL correctly. A national survey of gerontology and geriatric issues and trends in U.S. nursing program by Gilje et al. $(2007)^{[17]}$ addressed barriers to offering standalone geriatric/gerontological nursing course. The primary barriers identified in the study were curriculum overload, lack of interest among faculty, insufficient number of qualified faculty, and lack of clinical resources. ${ }^{[17]}$ More nursing schools in U.S. have turned in integrated of gerontological content in curricula instead of having a standalone gerontological nursing course, a trend that has continued in the schools examined in this report. For example, since initial data collection, nursing school A has subsequently changed from standalone to integrated curricula due to an overload issue. Our results suggest that it is critical that nursing schools with both integrated and standalone curricula routinely evaluate

Published by Sciedu Press gerontological content retention across nursing courses and identify gaps in knowledge. Deficits can then be remedied during nursing education, for example, through extra clinical experience and practice with case studies, resulting in a nursing workforce better prepared to provide quality care to geriatric populations. Importantly, this could be in either long-term or acute care settings. Literature from Canada and Australia supports gerontological curriculum in nursing and other health related professionals (e.g., social work) should provide students to have more knowledge and skills to be able to provide older adult care in a variety of settings. ${ }^{[16,28]}$

Recently, professional nursing organizations have sought to improve geriatric/gerontological nursing education through a number of cost-effective and easily disseminated programs, recommendations, and resources. In 2006, American Association of Colleges of Nursing (AACN) in partnership with Hartford Institute for Geriatric Nursing (HIGN) published milestone guidelines in gerontological nursing education, entitled, "Caring for an Aging America: A Guide for Nursing Faculty" that provides comprehensive approaches to enhancement of geriatric education including faculty expertise development, technology-based web-administered courses, design of clinical experiences through community partnerships, supporting student interest in gerontology area. ${ }^{[29]}$ The HIGN, in collaboration with AACN and other nursing organizations, has developed important geriatric related competencies and curricular related guidelines. ${ }^{[30]}$ For example, ConsultGeri, a clinical website from HIGN, provides free and easily accessible tools and video resources relating to clinical practice specific to older adult care. ${ }^{[31]}$ In addition, the Center for Excellence in the Care of Vulnerable Population under the National League for Nursing (NLN) has sought to address the special needs of older adults, Alzheimer's patients and their caregivers. ${ }^{[32]}$ The Advancing Care Excellence (ACE) programs in the NLN provide free classroom-ready materials such as unfolding cases and simulation scenarios.

\section{Limitations}

Our study provides information useful in informing the design of gerontology content in nursing curricula but has several limitations. First, the cross-sectional design inhibits our ability to study attitudes, career choices, and competencies over time. Second, the school with integrated curriculum had fewer participants, and a varying recruitment method that did not include compensation. Second, one of three participating nursing school has RN-BSN program. The survey link was sent out to RN-BSN students and thus this might affect the age variation (Mean $=24$, Median $=22$, range 19-51 years). We failed to identify how many study participants were RNBSN students because we did not intend to include the group 
but cannot exclude them in the nature of survey link distribution via the recruitment email in the nursing school $\mathrm{C}$ with integrated curriculum. Third, our study only included undergraduate nursing students; future research should explore the attitudes toward older adults and career choice of graduate students in advanced practice nursing programs and of nurse practitioners (NP). Approximately $90 \%$ of NPs are certified in primary care and often see older adults and their family caregivers in daily practice. ${ }^{[33]}$ As such, NP students are another key population to target with enhanced gerontological educational opportunities as either standalone or integrated curricula. Fourth, all three of our schools were in California somewhat limiting generalizability; nevertheless this provides critical information regarding nursing education in the United States. California has very diverse older population that is the largest in the United State at 4.2 million. Moreover, California anticipates a continuous increase in older adult population until $2050,{ }^{[34]}$ necessitating an increased number of nurses trained to care for this population. Future research should explore effective methods of teaching gerontological concepts and practices to nurses in a wider variety of settings in the United States and across the globe.

\section{Conclusion}

As healthcare continues to improve and the number of aging adults continues to rise, it is imperative that health care professionals, especially registered nurses, be knowledgeable of aging, the effects of aging, and health promotion in older adults to assist in maintaining older adults as thriving members of our communities and to avoid institutionalizing the elderly. The availability of the various roles of working with older adult populations in the community continues to evolve; nursing should be at the forefront in identifying these roles as well as developing programs to improve the lives of older adults.

Results indicated that nursing students who take more gerontology content related courses and/or have more experience working with older adults are more likely to consider a career in older adult care. However, these experiences do not necessarily need to be offered at part of standalone courses. To increase nursing students' interest in the gerontological nursing area, nursing schools in particular should provide more gerontology related courses as part of both mandated and elective nursing curricula.

\section{ACKNOWLEDGEMENTS}

The authors thank the students who generously donated their time to participate in the study. The authors also thank Michelle Chan for help develop web-survey tools.

\section{CONFlicts of InTEREST Disclosure}

No authors report conflict of interest.

\section{REFERENCES}

[1] Centers for Disease Control and Prevention. Healthy Aging at a glance 2015: Helping Older Americans achieve healthy and high-quality lives. Available from: https://www.cdc.gov/chronicdisease/resources/p ublications/aag/pdf/2015/healthy-aging-aag.pdf

[2] American Association of Colleges of Nursing. Nursing shortage fact sheet. Available from: http://www.aacn.nche.edu/Medi a/FactSheets/NursingShortage.htm https://doi.org/10 .1097/00000446-200409000-00032

[3] Mezey M, Harrington C, Kluger M. NPs in nursing homes: an issue of quality. Am J Nurs. 2004; 104(9): 71.

[4] Liu YE, Norman IJ, While AE. Nurses' attitudes towards older people: a systematic review. Int J Nurs Stud. 2013; 50(9): 1271-1282. PMid:23265870 https://doi.org/10.1016/j.ijnurstu. 201 2.11 .021

[5] Palmore E. The ageism survey: first findings. Gerontologist. 2001; 41(5): 572-575. PMid:11574698 https://doi.org/10.1093/ge ront/41.5.572

[6] Palmore EB. Ageism in Canada and the United States. J Cross Cult Gerontol. 2004; 19(1): 41-46. https://doi.org/10.1023/B: JCCG. $0000015098.62691 . \mathrm{ab}$

[7] Rupp DE, Vodanovich SJ, Crede M. The multidimensional nature of ageism: construct validity and group differences. J Soc Psychol.
2005; 145(3): 335-362. PMid:15960004 https ://doi .org/10.3 200/SOCP. $145 \cdot 3 \cdot 335-362$

[8] Fitzgerald JT, Williams BC, Halter JB, et al. Effects of a geriatrics interdisciplinary experience on learners' knowledge and attitudes. Gerontol Geriatr Educ. 2006; 26(3): 17-28. PMid:16446269 https://doi.org/10.1300/J021v26n03_02

[9] Flood MT, Clark RB. Exploring knowledge and attitudes toward aging among nursing and non-nursing students. Educational Gerontology. 2009; 35(7): 587-595. https://doi.org/10.1080/0360 1270802605333

[10] Allan LJ, Johnson JA. Undergraduate attitudes toward the elderly: The role of knowledge, contact and aging anxiety. Educational Gerontology. 2009; 35(1): 1-14

[11] Snyder JR. The influence of instruction on college students' attitudes toward older adults. Gerontol Geriatr Educ. 2005; 26(2): 69-79. https://doi.org/10.1300/J021v26n02_05

[12] Burbank PM, Dowling-Castronovo A, Crowther MR, et al. Improving knowledge and attitudes toward older adults through innovative educational strategies. J Prof Nurs. 2006; 22(2): 91-97. PMid:16564473 https://doi.org/10.1016/j.profnurs . 2006.01.007

[13] Holroyd A, Dahlke S, Fehr C, et al. Attitudes toward aging: implications for a caring profession. J Nurs Educ. 2009; 48(7): 374-380. https://doi.org/10.3928/01484834-20090615-04

[14] Stewart TJ, Roberts E, Eleazer P, et al. Reliability and validity issues for two common measures of medical students' attitudes to- 
ward older adults. Educational Gerontology. 2006; 32(6): 409-421. https://doi.org/10.1080/03601270600685628

[15] Olson MD. Gerontology content in MSW curricula and student attitudes toward older adults. Educ Gerontol. 2007; 33(11): 981-994. https://doi.org/10.1080/03601270701632230

[16] Algoso M, Peters K, Ramjan L, et al. Exploring undergraduate nursing students' perceptions of working in aged care settings: A review of the literature. Nurse Educ Today. 2016; 36(Supplement C): 275280.

[17] Gilje F, Lacey L, Moore C. Gerontology and geriatric issues and trends in U.S. nursing programs: a national survey. J Prof Nurs. 2007; 23(1): 21-29. PMid:17292130 https://doi.org/10.1016/j.pr ofnurs.2006.12.001

[18] Ferrario CG, Freeman FJ, Nellett G, et al. Changing nursing students' attitudes about aging: an argument for the successful aging paradigm. Educational Gerontology. 2008; 34(1): 51-66. https: //doi.org/10.1080/03601270701763969

[19] Paulson C. Educating for mindful perspectives on aging. J Nurs Educ. 2012; 51(6): 303-304. PMid:22658262 https://doi.org/10.3 928/01484834-20120522-01

[20] Eymard AS, Douglas DH. Ageism among health care providers and interventions to improve their attitudes toward older adults: an integrative review. J Gerontol Nurs. 2012; 38(5): 26-35. PMid:22420518 https://doi .org/10.3928/00989134-20120307-09

[21] Higgins I, Van Der Riet P, Slater L, et al. The negative attitudes of nurses towards older patients in the acute hospital setting: a qualitative descriptive study. Contemp Nurse. 2007; 26(2): 225-237. https://doi.org/10.5172/conu.2007.26.2.225

[22] Berman A, Mezey M, Kobayashi M, et al. Gerontological nursing content in baccalaureate nursing programs: comparison of findings from 1997 and 2003. J Prof Nurs. 2005; 21(5): 268-275. PMid:16179239 https://doi.org/10.1016/j.profnurs.2005.07.005

[23] Sofaer S, Shire A, Fortin J. GNEC evaluation brief: Multiplying change, ensuring all nurses learn to care well for older adults. Available from: http://www.aacn.nche.edu/geriatric-nursing /GNEC-Evaluation-Brief .pdf
[24] American Association of Colleges of Nursing. Recommended Baccalaureate Competencies and Curricular Guidelines for the Nursing Care of Older Adults. Available from: http://www. aacn.nche. edu/geriatric-nursing/AACN_Gerocompetencies.pdf

[25] Kogan N. Attitudes toward old people: the development of a scale and an examination of correlates. J Abnorm Soc Psychol. 1961; 62: 44-54. https://doi.org/10.1037/h0048053

[26] Lee YS. Ethnic differences in attitudes and bias toward older people comparing White and Asian nursing students. J Transcult Nurs. 2015; 26(2): 202-208. PMid:25297449 https : //doi .org/10.1177/10 43659614553514

[27] Lee YS, Shin SH, Greiner PA. Can education change attitudes toward aging? A quasi-experimental design with a comparison group. J Nurs Edu Prac. 2015; 5(9): 90-99.

[28] Hirst SP, Lane AM, Stares B. Gerontological Content in Canadian Nursing and Social Work Programs. Can Geriat J. 2012; 15(1): 8-15.

[29] American Association of Colleges of Nursing/John A Hartford Foundation. Caring for an Aging America: A Guide for Nursing Faculty. Available from: http://www .aacn.nche.edu/geriatric-nur sing/monograph.pdf

[30] The Hartford Institute for Geriatric Nursing. ConsultGeri-Try This: $₫$ Best Practices in Nursing Care to Older Adults Series. Available from: https://consultgeri.org/tools

[31] The Hartford Institute for Geriatric Nursing. ConsultGeri. Available from: https://consultgeri.org/

[32] National League for Nursing. The Center for Excellence in the Care of Vulnerable Populations. Available from: http://www.nln.or $\mathrm{g} /$ centers-for-nursing-education/nln-center-for-exc ellence-in-the-care-of-vulnerable-populations

[33] American Association of Nurse Practitioner. NP Fact Sheet. Available from: https://www.aanp.org/all-about-nps/np-fac $\mathrm{t}$-sheet

[34] US Census Bureau. An aging world 2015. Available from: https ://www . census .gov/content/dam/Census/library/ publications/2016/demo/p2095-2016-2011.pdf 